Peer review: This article has been subject to a double blind peer review process

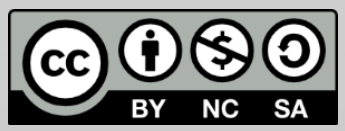

(C) Copyright: The Authors. This article is issued under the terms of the Creative Commons Attribution NonCommercial Share Alike License, which permits use and redistribution of the work provided that the original author and source are credited, the work is not used for commercial purposes and that any derivative works are made available under the same license terms.

\section{A Critical Reflection on the 28th International Biology Olympiad}

\author{
Branagh Crealock-Ashurst*, Leanne Williams, Kevin Moffat
}

School of Life Sciences, University of Warwick.

*Correspondence: $\underline{\text { b.crealock-ashurst.1@warwick.ac.uk }}$

\begin{abstract}
The 28th International Biology Olympiad (IBO) took place at the University of Warwick between 23 - 30 July 2017 with 264 international competitors (aged $14-18$ ) competing in a series of practical and theoretical exams devised by School of Life Sciences staff and colleagues from the Royal Society of Biology. These exams sought to provide an educational experience for the competing students and provide a robust theoretical and practical challenge to discriminate between abilities. Their secondary aim was to showcase complex biological concepts to further pique candidate's interest in biological science and encourage them to pursue careers in this area. The structure of practical and theoretical exams was underpinned by these pedagogical aims by applying a contextual narrative throughout the papers. Whilst a few logistical problems occurred, these did not impact the desired educational aim, leading to one of the most successful IBO's in recent years.
\end{abstract}

Keywords: pedagogy; Olympiad; examination; Education; Biology; reflection

\section{Introduction}

The International Biology Olympiad (IBO) ran from 23 - 30 July 2017, and comprised a series of competitive practical and theory exams for 264 students from 65 countries. This was the first time the event had been held in the United Kingdom. The University of Warwick, led by the School of Life Sciences (SLS), submitted a proposal to the Royal Society of Biology (RSB) and was chosen to host this prestigious international event. The partnership was specifically between SLS, Warwick conferences and the RSB. In terms of content, SLS were solely responsible for the design and implementation of the practical examinations only. Key team members from SLS are shown in Supplementary Table 1. 'To take part in the IBO, the students must be in the top four in the National Biology Olympiad in their individual countries' (Royal Society of Biology, 2017). 
National competitions are extremely competitive and for the UK over 7500 students entered the 2016-17 British Biology Olympiad (UK Biology Competitions, 2017). The top sixteen students came to Warwick in April 2017 to undertake three days of theoretical and practical skills development, culminating in challenging theory and practical examinations. The top four were selected to represent the UK. Following further training at the Natural History Museum, Kew Gardens and the University of Reading they were ready to compete on the International stage at the IBO in July.

There are several aims of the IBO (Royal Society of Biology, 2017) with the most important being:

- To provide an educational experience, as well as promote an interest in biology.

- To stimulate talented young people in the field of biology and help them on their way to a career in biological research.

- Be an opportunity for collaboration and inspiration between students, researchers and universities across national borders.

\section{Practical Examination Design}

Historically, the practical examination component of the IBO had been divided into four separate one and a half hour exams. The driving aim for Dr Leanne Williams and Professor Kevin Moffat was to devise practical exams that were a comprehensive test of understanding the scientific method. This was achieved through assessment criteria involving problem solving, practical skills and the ability to think laterally across multiple components. The intention was not to test the recall of assumed knowledge nor the application of 'typical' practical techniques. Exams were reduced to three separate two hour exams to allow for an increase in complexity, driven by a multistage contextual narrative.

The botany practical (developed by Dr Miriam Gifford) explored the origins of plants and their taxonomy. This tested the ability of students to show their understanding of the topic by completing an array of tasks, which increased in detail and complexity. These included plant taxonomy/morphology and seed/embryo development. Assessed skills were sample handling and dissection, interpretation, reasoning and time management.

I wanted to use this as a chance to test their full range of practical botany skills, importantly on all aspects of plant growth and development. From the tiniest developing seed to seven hundred million years of botanical 
evolution, I wanted to encourage students and those involved to have a greater appreciation of plant science through the fascinating structures observed (Gifford, 2017).

The biochemistry practical (developed by Dr Stuart Allen and Dr Michael Baker) explored a clinical scenario of a hypothetical family with a genetic metabolic disorder. This required candidates to understand a hypothetical clinical scenario and relate this to enzyme biochemistry data that they had devised experimentally to underpin protein and genetic analysis. Assessed skills were technical accuracy, data handling, interpretation, reasoning and time management.

We developed a clinical scenario based on blood tests that are characteristic of disease, a biochemical assay to determine the extent of the disease state and a genetic component that linked the disease symptoms and biochemical activity to the genetics of a fictitious family. The difficulty was that each component of the practical had to be understood and completed to be able to determine the disease state of the fictitious patients. The practical tested mathematical skills in context of a clinical scenario, practical skills in the form of the biochemical assay, as well as an understanding of how the components linked together to determine the genetic backgrounds of the patients (Allen, 2017).

Finally, the developmental physiology paper (developed by Dr Leanne Williams and Professor Kevin Moffat) investigated the external and internal morphology of Calliphora vicina - a bottle fly larva. Candidates worked through a series of tasks which allowed them to develop an understanding of the organism and quickly develop the skills needed for subsequent tasks as their technical difficulty increased. The requirements were to identify and isolate intact specific tissues of the organism, to identify the dorsal vessel (heart) and devise and perform an experiment to test the effects of various pharmacological agents. The skills assessed were fine dissection, microscopy, experimental design, reasoning and resilience.

We wanted to create a completely skills based practical that required no previous theoretical knowledge. There were two parts to the practical that required observational skill to achieve relatively simple aims. The second part particularly, needed the students to theoretically design the experiments based on our stated criteria and give expected outcomes. Finally, students had to perform the experiments and display their data graphically. The outcomes we wanted were for the students to experience the incredible internal anatomy of a maggot, and to appreciate the scientific method (Moffat, 2017). 
During the week prior to the IBO a sub-jury comprising six members and led by the IBO chair, met to review the practical and theoretical materials. The scientific content, the rigour of the exams and any complications associated with translation were identified, scrutinised, critiqued and evaluated. Exams cannot be presented to the IBO jury without the consent of the sub-jury. This was a vital component in the final stages of the practical exam development and played an essential role in the presentation and justification of the exams to the international jury on the Monday of the IBO week.

As has been previously stated, one of the key aims of the IBO is to provide an educational experience (Royal Society of Biology, 2017) and this heavily influenced the design of the practical and theoretical exams. A common theme between the exams was to encourage the students to be able to 'learn' from their experience. It was not expected that students would come into their exam knowing all of the answers and the hope was that they would leave their exams inspired to continue learning. This pedagogical approach to examination was unique to the IBO 2017 and will hopefully be a recurring theme in the years' to come.

\section{Practical Exam Reflection}

The jury report for the practical exams praised the content and the approaches taken by academic SLS staff to ensure that a narrative was shown throughout the paper. Compliments were given on the novel structure of the papers and the educational value. During the practical exams a team of inspectors attended all exams to consider the following:

a) How scientifically valid the exams were and whether they adhere to the IBO syllabus.

b) How the exams went on the day and how any incidents were dealt with.

c) Whether marks should be awarded/deducted from individual students due to conduct/circumstances in the exam rooms.

The inspectors' post-exam report praised how smoothly the session went in terms of transport, delivery and assessment. It was determined that the practical exams were of an excellent standard and some of the best in Olympiad history. In the botany exam several students did not fill in their paper identifiers and attempted to remove exam material from the room, leading to the misidentification of a student's completed exam. It was also noted that that some translations were not sufficient for students to follow and, in a number of cases, jury members included the official English version of the exam alongside their translation. Pleasingly 
no students seemed to struggle answering the exam, although mistranslation of questions cannot be ruled out.

\section{Results}

Each of the three practical exams had its own pedagogical aims. The results of the exams were explored to determine if answers matched the examiners' expectations. Figure 1 (a) highlights the difficulty of the biochemistry exam with the average standard deviation (sd, 0.0$)$ being skewed to the left and a high density of greater than 0.3. A large proportion of students performed slightly better ( $1.0 \mathrm{sd}, 0.2$ density) and slightly worse (-1.0 sd, 0.3 density) than average. Most students were only able to score low marks (as some students achieved over $3.0 \mathrm{sd}$ higher than their cohort). Pedagogically it shows that those students who were able to fully understand each component of the practical were able to achieve the top marks.

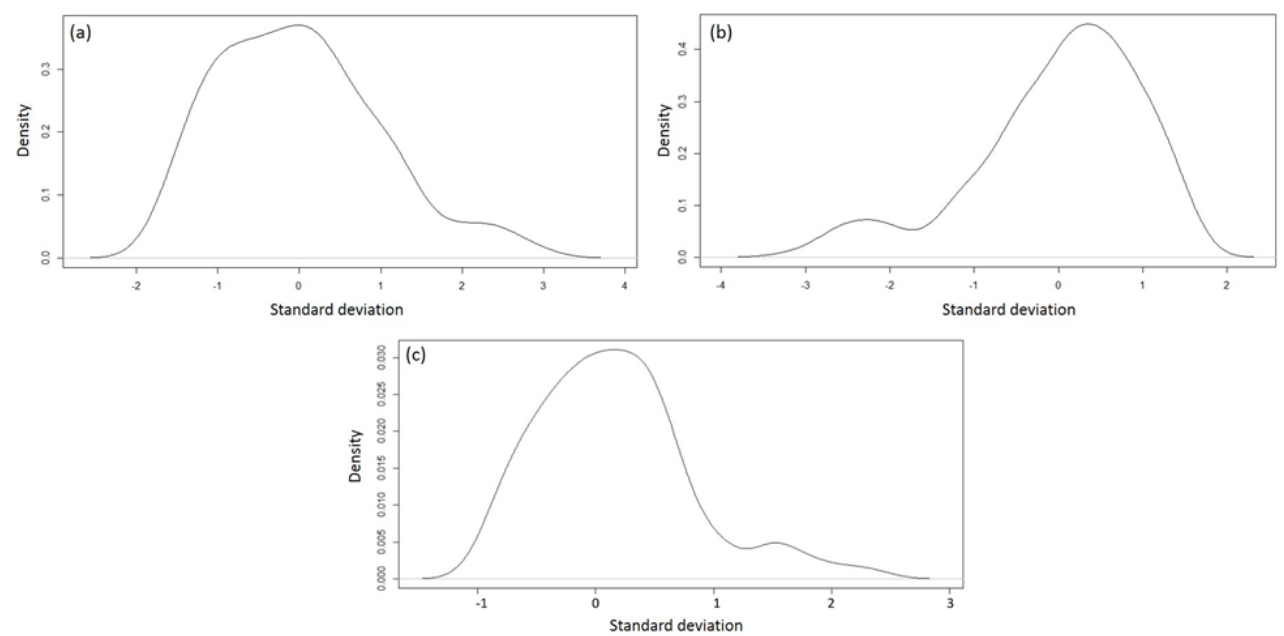

Figure 1: Standard deviation scores of the competitors ( $N=241)$ throughout the practical exams for biochemistry (a), botany (b) and developmental physiology (c). The y axes show the density of students whereas the $x$ axes show the standard deviation distribution, with zero showing the average standard deviation compared to the mean mark and the digits representing standard deviations above and below the mean mark. This figure was produced by Matt Johnston and Joshua Hodgson using the publicly available list of results available online at: http://ibo2017.org/images/ResultsIBO2017Full inc Iran.pdf. 
Figure 1 (b) shows a comparatively easier botany paper due to the right handed skew of the distribution. Nearly half of the students (over 0.4 density) scored highly with many more doing better than average (1.0 sd, just under 0.4 density). Those students that performed poorly drop down sharply below the average, suggesting that most students performed well in this exam. However, a small minority of competitors performed very badly (nearly -4.0 sd below average), highlighting the previously discussed translation issues. It could be suggested that those students who did not have English as their native language struggled in certain sections of the botany exam, leading to the perceived lower scores. Pedagogically, these results show that many students succeeded in the full range of botany practical skills, and for those that did not perform as well, hopefully this served as a learning exercise to invest time in further exploring their botanical knowledge.

Figure 1(c) shows that many students struggled to perform very well in developmental physiology (left handed skew). This practical had the fewest students performing averagely well (just over 0.3 density compared to biochemistry and botany - nearly 0.4 and over 0.4 respectively). This practical saw a greater spread of marks, highlighted by the condensed data with huge drop offs of student density $1.0 \mathrm{sd}$ above and below the average. Pedagogically this practical saw the top students discriminated in terms of practical skill, highlighting their superior abilities compared to the rest of their cohort.

Overall, the response to the IBO 2017 practical exams was very positive. Where issues were identified, all were resolved in a manner that did not interfere with the students' final results, leading to the conclusion that the key aim of achieving a pedagogical approach was successful. This educational experience was essential to the students' learning and the three aims of the IBO (Royal Society of Biology, 2017) can be considered to have been met in the practical exams. The pedagogical approach to examination by extending the exam length and weaving a narrative throughout the papers serves to accomplish the first aim in its entirety. Secondly these exams provided an insight into current areas of contemporary research, hopefully provoking the students to further explore these areas in their future. Finally the third aim was accomplished through not just partaking in the exams but by attendance at the IBO itself.

These students came to the University of Warwick to compete in a competition, but left having experienced so much more. The IBO will have been a positive experience and showed the advantages that a university education brings, such as the opportunity to meet other like-minded 
people and to research solutions into problems that affect the world around us. The fact that the University of Warwick is an internationally acclaimed university will have also shown the students the potential of collaboration on a global scale, especially in the Life Sciences. We have high hopes that this IBO will have inspired students in the UK to compete in future national biology competitions and to consider future study into the Life Sciences (Crealock-Ashurst, 2017).

\section{Theoretical Exam Reflection}

Two theory exams were delivered to the competitors via the technology platform Joda, a platform that has been used in previous years (Helfer, 2016). This software was used for the presentation and translation of the theoretical exams and for the translation of the practical exams. The exams were written by two former UK IBO competitors - Matt Johnston and Joshua Hodgson. The aim for these theory exams was to challenge the competitors' understanding of fundamental biological science / scientific theory and to deliver a pedagogical approach akin to the practical exams. Matt Johnston outlined their approach to the theory exams:

We wanted to make theory exams easier than previous years. We wanted students to score $75 \%$ (half way between $50 \%$ (chance) and 100\%). We wanted to make the science a little less sanitised than previous IBOS, so that students would learn something as they did it. They may see something which is cool and want to read more (e.g. Turing patterns). And ... we wanted to showcase British science (Johnston, 2017).

The content for the IBO theory exams is strictly controlled by the IBO syllabus as shown in Figure 2 and all questions are required to focus on reasoning, problem solving and understanding (Morélis, 2016). The creators of the exams therefore sought to include lots of examples of 'British science discovery' to develop their pedagogical approach to examination and the IBO requirement for an educational experience. 
(3) Theoretical questions should cover the following topics in the indicated proportions.

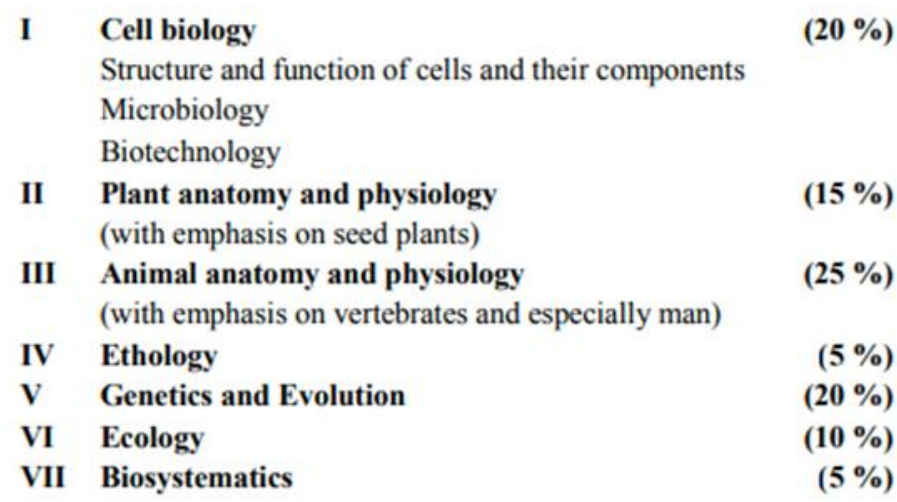

Figure 2: The theoretical questions and desired percentage proportions.

Again, the sub-jury performed a pre-exam inspection of the questions before inspection and translation by the jury. For the practical examinations, a post exam report on the conditions in the exam was provided by the inspectors. Both were very satisfactory with the examiners praising the layout of questions and the approaches used to encourage students to further research the topics post IBO. This can be considered to have accomplished the IBO aim of providing an educational experience and provided stimulation to the students in the field, encouraging them to further their careers in biological research. No major IT service problems were encountered and all students were able to connect and finish their exams properly via the exam provider Joda. 'This was singly the best IT delivery across the exam and the jury room that the IBO had ever seen' (Moffat, 2017).

\section{Conclusions}

As outlined in the introduction, the IBO 2017 sought to continue the IBO tradition of providing three main aims (Royal Society of Biology, 2017) and it can be concluded that all three of these aims were met. In both the theoretical and practical exams a considered approach was used to provide not only an educational experience for the students, but also to encourage future careers in biological research, thus meeting the first two aims above. Whilst the third aim was not accomplished by the action of taking part in exams, the students spending a week of networking and interacting also accomplishes the aim to collaborate and inspire in the future. These students will go back to their home countries and most commonly onto university education in related fields, where they will hopefully stay in contact with their fellow IBO competitors thus 
accomplishing the goal of communication between universities across national borders.

Whilst the IBO will not be held in the UK again for a long time, it has hopefully inspired younger students in this country to further their interest in biology and encourage them to partake in future events, for a chance to be a part of what is considered to be the greatest biology competition in the world. Best of luck to Iran for the 29th International Biology Olympiad 2018 to be held in Tehran!

\section{Acknowledgements}

Many thanks to Jenny Bowskill for her help throughout IBO week helping with the management of the logistics. Thanks must also go to Leanne Williams and Kevin Moffat for their hard work in ensuring the IBO went down so smoothly and for their help in writing this reflection. The IBO would not have happened if not for the extremely hard work of the SLS technical lab team consisting of: Gill Scott, Dave Vaughn, Tracy McCusker, Geraldine Keene and Razia Iqbal - they were and are all stars. I'd also like to thanks the entirety of SLS for supporting and helping us during IBO and for volunteering their help and expertise. Finally, many thanks Charlotte Beesley for keeping me sane during the many months leading up to and during the IBO. Couldn't have done it without you!

\section{List of Figures}

Figure 1: Standard deviation scores of the competitors ( $N=241)$ throughout the practical exams for biochemistry (a), botany (b) and developmental physiology (c).

Figure 2: The theoretical questions and desired percentage proportions.

\section{Appendix}

Supplementary Table 1: Key team members from SLS involved in IBO preparation and delivery. This number was supplemented with 45 student other volunteers. 


\begin{tabular}{|c|c|c|}
\hline $\begin{array}{c}\text { Academic Staff } \\
\text { (Led by Author } \mathbf{2} \text { and 3) }\end{array}$ & $\begin{array}{c}\text { Logistical Staff } \\
\text { (Led by Author 1) }\end{array}$ & $\begin{array}{c}\text { Technical Lab Staff } \\
\text { (Led by Gillian Scott) }\end{array}$ \\
\hline Dr Stuart Allen & Dr Rebecca Allen & Dorota Boehm \\
\hline Dr Michael Baker & Jenny Bowskill & Razia Iqbal \\
\hline Dr Lorenzo Frigerio & $\frac{\text { Branagh Crealock- }}{\text { Ashurst }}$ & Andrew Jukes \\
\hline Dr Miriam Gifford & Dr Rebecca Freeman & Geraldine Keene \\
\hline Professor Kevin Moffat & Jeanette Horton & Tracy McCusker \\
\hline Dr Robert Spooner & & Gillian Scott \\
\hline Dr Leanne Williams & & Dave Vaughan \\
\hline
\end{tabular}

\section{References}

Royal Society of Biology (2017), The International Biology Olympiad, http://ibo2017.org/, accessed 3 August 2017

UK Biology Competitions (2017), British Biology Olympiad, http://www.ukbiologycompetitions.org, Accessed 10 August 2017

Gifford, M. (Personal communication, 11 August 2017)

Allen, S. (Personal communication, 16 August 2017)

Moffat, K. (Personal communication, 16 August 2017)

Crealock-Ashurst, B. (2017), Bayer Engaging the Next Generation, http://cropscience.bayer.co.uk/news-and-opinion, accessed 23

September 2017 (not yet published)

Helfer, J. (2016), Joda, https://ibo2017.jonashelfer.com, accessed 3 August 2017

Johnston, M. (Personal communication, 3 August 2017)

Morélis, H. (2016), Designing a reliable Theory Test for the International Biology Olympiad, http://www.iboinfo.org/pdf/Designing\%20a\%20reliable\%20IBO\%20Theory-HMroct2011.pdf, accessed 3 August 2017

\section{To cite this article:}

Crealock-Ashurst, B. et al. (2017). A Critical Reflection on the 28th International Biology Olympiad. Exchanges: the Warwick Research Journal, 5(1), 127-136. Retrieved from:

http://exchanges.warwick.ac.uk/index.php/exchanges/article/view/221 